\title{
Multivariate Spectroscopic Determination of the Lamivudine-Zidovudine Association
}

\author{
Gilcélia A. Cordeiro, ${ }^{a}$ Noemi Nagata, ${ }^{a}$ Iara Messerschmidt, ${ }^{a}$ Patricio Peralta-Zamora*,a \\ and Letícia N. C. Rodrigues ${ }^{b}$
}

\author{
${ }^{a}$ Departamento de Química, Universidade Federal do Paraná, 81531-990 Curitiba-PR, Brazil \\ ${ }^{b}$ Departamento de Ciências Exatas e da Terra, Universidade Federal de São Paulo, \\ 09972-270 Diadema-SP, Brazil
}

\begin{abstract}
A determinação espectroscópica multivariada da associação lamivudina-zidovudina foi realizada por regressão de mínimos quadrados parciais. O modelo foi desenvolvido a partir de 20 misturas sintéticas utilizando-se dados espectrais centrados na média adquiridos entre 190 e $350 \mathrm{~nm}$ e 3 variáveis latentes. A validação externa foi realizada a partir de 6 misturas sintéticas, observando-se erros médios de previsão de aproximadamente $1 \%$. Na análise de medicamentos foram obtidos bons resultados, com erros de previsão inferiores a 10\%. A metodologia multivariada foi validada de acordo com os critérios do International Conference on Harmonization (ICH), demonstrando precisão, exatidão e robustez compatíveis com a legislação vigente.
\end{abstract}

The multivariate spectroscopic determination of lamivudine-zidovudine associations was carried out by partial least square regression (PLS). This model was developed from 20 synthetic mixtures using mean-centered spectral data acquired from 190 to $350 \mathrm{~nm}$ and with 3 latent variables. External validation was performed with 6 synthetic mixtures providing prediction errors close to $1 \%$. Moreover, the analysis of commercial drugs showed good results with prediction errors lower than $10 \%$. The multivariate methodology was validated according to International Conference on Harmonization (ICH) criteria, demonstrating precision, accuracy and robustness within legal requirements.

Keywords: lamivudine, zidovudine, electronic spectroscopy, multivariate calibration

\section{Introduction}

Electronic spectroscopy is an analytical technique of recognized importance, mainly due to its low instrumental and operational costs, high analytical throughput, and a sensitivity that meets many analytical requirements. Unfortunately, its low selectivity hinders many applications, which is a consequence of the frequently observed spectral interferences. ${ }^{1,2}$

In the pharmaceutical industry, for instance, there is a need for fast and accurate analytical methods, mainly for the establishment of routines governing the analytical control of raw materials and products. Many pharmaceutical products contain the association of two or more drugs with a great number of auxiliary substances (excipients), a fact that increases both the complexity of the matrix and the difficulty of applying spectroscopic methods.

*e-mail: zamora@ufpr.br
Consequently, many analytical routines are based on chromatographic methods, which are relatively expensive and time-consuming. ${ }^{3}$

In light of these facts, the development of strategies to overcome the problem of spectral interferences is important, especially to improve the analytical potential of the electronic spectroscopy. With this purpose in mind, there are several alternatives that can be used, including the preliminary separation of the analyte from the interfering matrix ${ }^{4}$ the chemical derivatisation of the analyte (formation of a derivative that absorbs in a non-interfering spectral region), ${ }^{5}$ the application of spectral derivative methods, ${ }^{6}$ and the use of multivariate calibration tools. ${ }^{7}$

Recently, several reports on the spectroscopic determination of drugs in pharmaceutical formulations by using partial least squares regression (PLS) have been published. ${ }^{1,8-10}$ The results from these reports attest to the suitability of the chemometric approach for the resolution of complex multicomponent mixtures. 
The aim of this study is the development of a new analytical methodology for the quality control of pharmaceutical formulations containing lamivudine and zidovudine using UV-Vis spectroscopy and partial least squares regression. Zidovudine (AZT, 3'-azido-3'-deoxythymidine) and lamivudine (3TC, 2'-deoxy-3'-thiacytidine) are synthetic nucleoside analogues with activity against the human immunodeficiency virus (HIV). AZT and 3TC are frontline therapies for the treatment of HIV infection and have become available in a combination tablet, containing $300 \mathrm{mg}$ of AZT and $150 \mathrm{mg}$ of 3TC per dose. ${ }^{11}$

Typically, the quantification of AZT and 3TC in pharmaceutical formulations is carried out by liquid chromatography according to official protocols from the United States Pharmacopoeia. ${ }^{12}$ Additionally, several chromatographic methods based on UV-Vis detection have been recently validated, ${ }^{13-15}$ including micellar electrokinetic chromatography (MEKC) $)^{16}$ and high performance thinlayer chromatography (HPTLC). ${ }^{17}$

Even with several reports attesting to the suitability of multivariate spectroscopic routines for the quality control of pharmaceutical products, ${ }^{7}$ studies involving AZT-3TC associations were not found in the current specialized literature. To the best of our knowledge, just one article reported the spectrophotometric determination of this association using a derivative method. ${ }^{18}$

\section{Experimental}

\section{Reagents}

Zidovudine and lamivudine were kindly provided by Cristália Produtos Químicos e Farmacêuticos Ltda. (Itapira, SP, Brazil) with a purity of $99 \%$. Stock solutions were prepared by direct dissolution of the drugs in deionised water.

The reference (Biovir, GlaxoSmithKline Brasil Ltda, Rio de Janeiro, RJ, Brazil) and generic (zidovudine/lamivudine, Farmanguinhos Laboratory, Rio de Janeiro, RJ, Brazil) drugs, containing $300 \mathrm{mg}$ of AZT and $150 \mathrm{mg}$ of 3TC each, were purchased from a local drugstore in Brazil.

Acetonitrile (JT Baker), methanol (Merck) and deionised water (Milli- ${ }^{\circledR}$, Millipore, Billerica, MA, USA) were of HPLC grade. Other chemicals were of analytical/reagent grade.

\section{Equipments and software}

Electronic absorption measurements were carried out on a Shimadzu (2410 PC, Kyoto, Japan) spectrophotometer using $1.00 \mathrm{~cm}$ quartz cells. The spectral data were recorded between 190 and $300 \mathrm{~nm}$ using a spectral resolution of $0.5 \mathrm{~nm}$ (221 points per spectrum).

High performance liquid chromatography (HPLC) analyses were carried out on a Varian 920-LC analytical chromatograph equipped with an autosampler, a quaternary gradient pump and a UV-Vis detector (265 nm). Routine chromatographic separations were performed on a Varian Cromosorb C18 column $(5 \mu \mathrm{m}, 250 \times 4.6 \mathrm{~mm})$.

The data treatment was carried out using Origin Pro 6.1 software (OriginLab). PLS models were developed by using PLS-Toolbox 3.0 (Eigenvector Research, Inc.) operating in Matlab 6.5 (Math Work Inc.).

\section{Procedures}

\section{Conventional calibration}

Initially, three conventional calibration systems were developed by using six synthetic mixtures containing 10.00 to $35.00 \mathrm{mg} \mathrm{L}^{-1}$ of zidovudine and 5.00 to $20.00 \mathrm{mg} \mathrm{L}^{-1}$ of lamivudine in deionised water. Individual analytical graphs (method 1) were elaborated by plotting the absorbance registered at the maximum absorption wavelength (266.0 $\mathrm{nm}$ for zidovudine and $197.0 \mathrm{~nm}$ for lamivudine) against the concentration of the standard solutions. In the derivative mode (method 2), the analytical graphs were created in a similar way, using the first-derivative signal registered for zidovudine at the zero-crossing wavelength of lamivudine and vice versa. The third conventional methodology (method 3) involved Vierordt's method, ${ }^{19}$ which is based on the additivity of the Lambert-Beer's law. The absorbance of the mixed samples was measured at two suitable wavelengths, and the concentration of each compound was calculated from the following equations:

$$
\begin{aligned}
& \mathrm{A}(266 \mathrm{~nm})=\left(\mathrm{a}_{\mathrm{AZT}, 266 \mathrm{~nm}} \times \mathrm{C}_{\mathrm{AZT}}\right)+\left(\mathrm{a}_{3 \mathrm{TC}, 266 \mathrm{~nm}} \times \mathrm{C}_{3 \mathrm{TC}}\right) \\
& \mathrm{A}(271 \mathrm{~nm})=\left(\mathrm{a}_{\mathrm{AZT}, 271 \mathrm{~nm}} \times \mathrm{C}_{\mathrm{AZT}}\right)+\left(\mathrm{a}_{3 \mathrm{TC}, 271 \mathrm{~nm}} \times \mathrm{C}_{3 \mathrm{TC}}\right)
\end{aligned}
$$

where A denotes the absorbance of the mixture, a is the absorption coefficient $\left(\mathrm{L} \mathrm{mg}^{-1} \mathrm{~cm}^{-1}\right)$, optical path is $1.00 \mathrm{~cm}$ and and $\mathrm{C}$ is the concentration $\left(\mathrm{mg} \mathrm{L}^{-1}\right)$.

The predictive capacity of these conventional calibration methods was evaluated by analysing six synthetic mixtures, containing 19.00 to $29.00 \mathrm{mg} \mathrm{L}^{-1}$ of zidovudine and 11.00 to $13.00 \mathrm{mg} \mathrm{L}^{-1}$ of lamivudine.

\section{Multivariate calibration}

Multivariate calibration models were developed with 20 synthetic mixtures containing 19.00 to $29.00 \mathrm{mg} \mathrm{L}^{-1}$ of zidovudine and 10.00 to $14.00 \mathrm{mg} \mathrm{L}^{-1}$ of lamivudine (Figure 1). 
The modelling amplitude was chosen taking into account the nominal concentration of AZT and 3TC in commercial medications (sample 13) and a maximal variation of $\pm 20 \%$. Additionally, six synthetic mixtures were prepared and reserved as an external validation set (Figure 1).

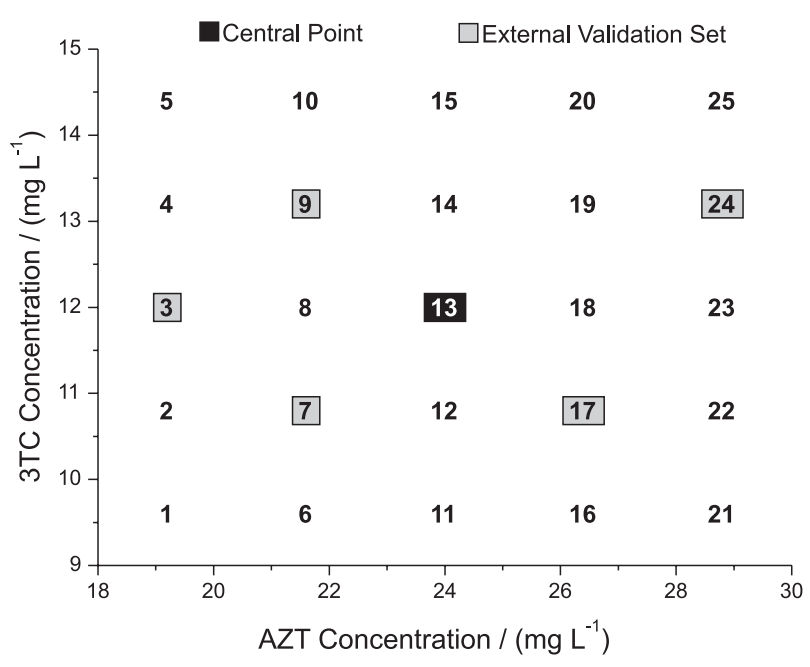

Figure 1. Synthetic mixtures of AZT and 3TC used as calibration and external validation sets in the development of multivariate calibration models.

Several signal pre-treatment systems were evaluated, including mean-centered, Savitski-Golay smoothing and first derivative. The number of latent variables (LV) was chosen taking into account the minimization of the root mean standard error of cross validation (RMSECV) value, a parameter calculated from the results of a leave-one-out cross-validation routine (equation 3 ). To avoid the creation of over-fitted models, a minimum number of latent variables was preferred, avoiding values with low captured variance.

RMSECV $=\sqrt{\frac{\sum_{i=1}^{n}\left(y_{i}-\hat{y}_{i}\right)^{2}}{n}}$

where $y_{i}$ and $\hat{y}_{i}$ represent the real and estimated concentrations, respectively.

\section{Validation}

The validation of the spectroscopic multivariate model was carried out according to guidelines from the International Conference on Harmonization (ICH), ${ }^{20}$ which includes evaluations of precision, accuracy, linearity and robustness. Precision was appraised at two different levels (intra-day repeatability and inter-day intermediate precision) by triplicate analysis of three synthetic mixtures containing high (AZT: $29.0 \mathrm{mg} \mathrm{L}^{-1}$, 3TC: $14.0 \mathrm{mg} \mathrm{L}^{-1}$ ), medium (AZT: $24.0 \mathrm{mg} \mathrm{L}^{-1}$, 3TC:
$12.0 \mathrm{mg} \mathrm{L}^{-1}$ ) and low (AZT: $19.0 \mathrm{mg} \mathrm{L}^{-1}$, 3TC: $10.0 \mathrm{mg} \mathrm{L}^{-1}$ ) analyte concentrations. Accuracy was evaluated by recovery studies using the same three synthetic mixtures. Finally, the robustness of the method was evaluated by analysis of one synthetic mixture containing $24.0 \mathrm{mg} \mathrm{L}^{-1}$ of AZT and $12.0 \mathrm{mg} \mathrm{L}^{-1}$ of 3TC in several $\mathrm{pH}$ values (3.2 to 10.1 ), temperature $\left(5\right.$ to $\left.60^{\circ} \mathrm{C}\right)$ and measurement time $(0$ to $90 \mathrm{~h})$ conditions.

\section{Analysis of commercial drugs}

Twenty tablets were individually weighed to obtain their representative average weights $(774.1 \mathrm{mg})$ and then finely powdered and mixed. For spectroscopic analysis, a quantity of the powder equivalent in mass to one tablet was accurately weighed and dissolved in $1000.0 \mathrm{~mL}$ of deionised water. An aliquot of $2.0 \mathrm{~mL}$ was transferred to a $25.0 \mathrm{~mL}$ volumetric flask and filled up to the mark with deionised water. The spectra were obtained using the same conditions described previously.

For chromatographic analysis, a quantity of the powder equivalent in mass to one tablet was accurately weighed and dissolved in $100.0 \mathrm{~mL}$ of methanol. An aliquot of $0.2 \mathrm{~mL}$ was transferred to a $25.0 \mathrm{~mL}$ volumetric flask and filled up to the mark with (methanol:water:acetonitrile, 49:44:7 v/v/v) mobile phase. The chromatographic determinations were performed under isocratic conditions, using the procedure described by Uslu and Özkan ${ }^{18}$ with modifications. All analyses were carried out in triplicate.

\section{Results and Discussion}

\section{Conventional calibration}

The significant spectral interference between AZT and 3TC is clearly evident in the spectral data shown in Figure 2. In the first analysis, the serious overlap observed in the zeroorder spectra hinders the simultaneous determination of AZT and 3TC, which emphasizes the necessity of a more discriminating calibration system. The great similarity between the spectral data of commercial drugs and synthetic mixtures, however, indicates an insignificant spectral interference from chemical excipients, which suggests the suitability of current calibration models.

Three conventional calibration systems were used to determine the concentrations of AZT and 3TC in six synthetic mixtures. The results (Table 1) confirmed bad predictions of the models constructed from zero-order spectra (method 1), due to the spectral interference earlier mentioned. Under these conditions, relative mean errors higher than 50\% were routinely observed for both drugs. 
Table 1. Relative mean errors $(n=6)$ in the determination of AZT and 3TC in synthetic mixtures from the validation set by conventional calibration systems

\begin{tabular}{lccccc}
\hline Calibration method & \multicolumn{2}{c}{$\mathrm{r}$ (wavelength) } & & \multicolumn{2}{c}{ Relative mean error $(\%)$} \\
\cline { 2 - 5 } & AZT & 3TC & AZT & 55.2 & 3TC \\
\hline Method 1 & $0.999(266.5 \mathrm{~nm})$ & $0.999(197.0 \mathrm{~nm})$ & 2.0 & 27.5 \\
Method 2 & $0.998(248.8 \mathrm{~nm})$ & $0.997(266.2 \mathrm{~nm})$ & 2.1 & 2.3 \\
Method 2 (with smoothing) & $0.998(248.8 \mathrm{~nm})$ & $0.997(266.2 \mathrm{~nm})$ & 3.8 & 10.8 \\
Method 3 & - & - & & 3 \\
\hline
\end{tabular}

$\mathrm{r}=$ regression coefficient; Method 1: Individual analytical graphs based on zero-order spectra. Method 2: Individual analytical graphs based on firstderivative spectra. Method 3: Vierordt's method.

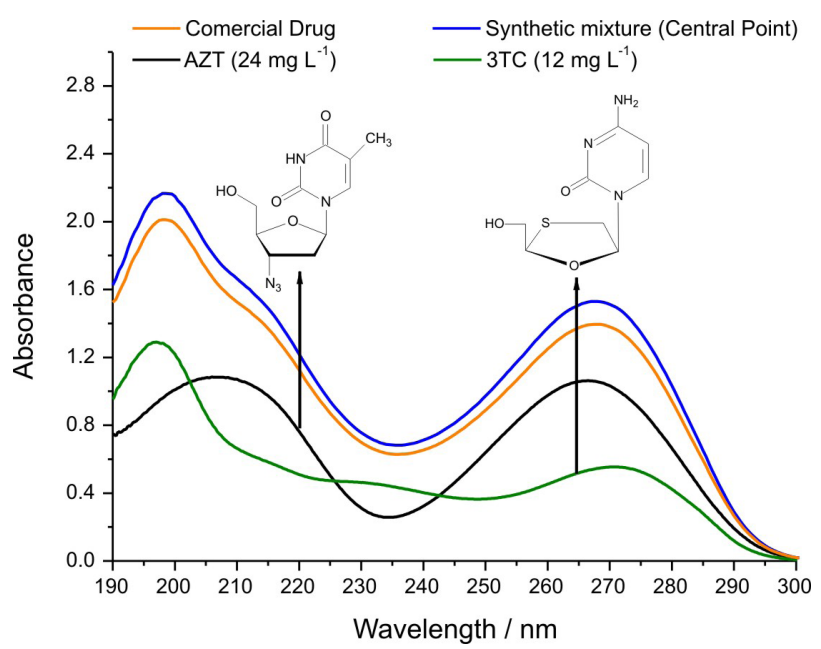

Figure 2. Spectral profiles of aqueous solutions of AZT, 3TC, synthetic mixture and commercial drug.

The development of individual analytical models based on first-derivative spectra (method 2 ) reduces the prediction errors, mainly for AZT determinations. Even when the spectral interference is minimized by working at zerocrossing wavelengths, the mean relative prediction error observed in the 3TC determinations was still very high (about $30 \%$ ). This result was probably the consequence of the decreased sensitivity and signal/noise ratio, which are both characteristics of derivative methods. Processing the data by Savitzki-Golay smoothing drastically reduced the prediction errors to approximately $2 \%$.

Upon the application of the conventional methodology based on Vierordt's method (method 3), a good predictive capacity was observed for AZT. In contrast, 3TC determination by this method leads to mean errors (10.8\%) that are incompatible with Brazilian legislation ${ }^{21}$ which requires a maximal discrepancy of $5 \%$.

\section{Multivariate calibration}

Several multivariate models were developed using three pre-processing systems and different numbers of latent variables (Table 2). With six synthetic mixtures used as an external validation set, low prediction errors were observed in all conditions, a result that demonstrated the ability of the PLS-2 algorithm to overcome problems related to overlapped spectral signals. For subsequent studies, the model developed using three latent variables and meancentered spectral signals was selected, mainly due to the lower prediction errors observed at these conditions (AZT: 1.26\%; 3TC: 0.87\%).

Table 2. Relative mean errors $(n=6)$ in the determination of AZT and $3 \mathrm{TC}$ in synthetic mixtures from the validation set by multivariate calibration systems

\begin{tabular}{cccccc}
\hline & \multicolumn{4}{c}{ Pre-processing } \\
\cline { 2 - 3 } LV Number & \multicolumn{2}{c}{ Mean centered } & & \multicolumn{2}{c}{ Smoothed and first derivate } \\
\cline { 2 - 3 } \cline { 2 - 3 } & AZT & 3 TC & & AZT & 3 TC \\
\hline 2 & 1.25 & 1.93 & & 1.54 & 1.62 \\
3 & 1.26 & 0.87 & & 1.40 & 1.52 \\
4 & 1.43 & 0.97 & & 1.38 & 1.05 \\
6 & 1.49 & 0.86 & & 1.47 & 1.11 \\
\hline
\end{tabular}

The RMSECV evolution as a function of the number of latent variables (LVs) is shown in Figure 3. According to the data in this figure, the introduction of two latent variables (LVs) significantly reduces the RMSECV value, improving the prediction capacity of the multivariate model. Moreover, the variance captured by the first two LVs represents $99.64 \%$ of the total variance of the Y block (AZT and $3 \mathrm{TC}$ concentrations) and $99.95 \%$ of the total variance of the X block (spectral data). The introduction of a third LV contributes $0.01 \%$ of the spectral data variance, increasing the total captured variance of the Y block up to $99.79 \%$.

The great similarity observed between the loading of the first LV (Figure 4) and the spectral profile of 3TC (Figure 2), and between the loading of the second LV and the spectral data of AZT, implies that practically all relevant spectral information associated with 3TC (and AZT) can be captured by just one latent variable, which results from the linear combination of the original variables. The presence of outliers was evaluated by examination of the 


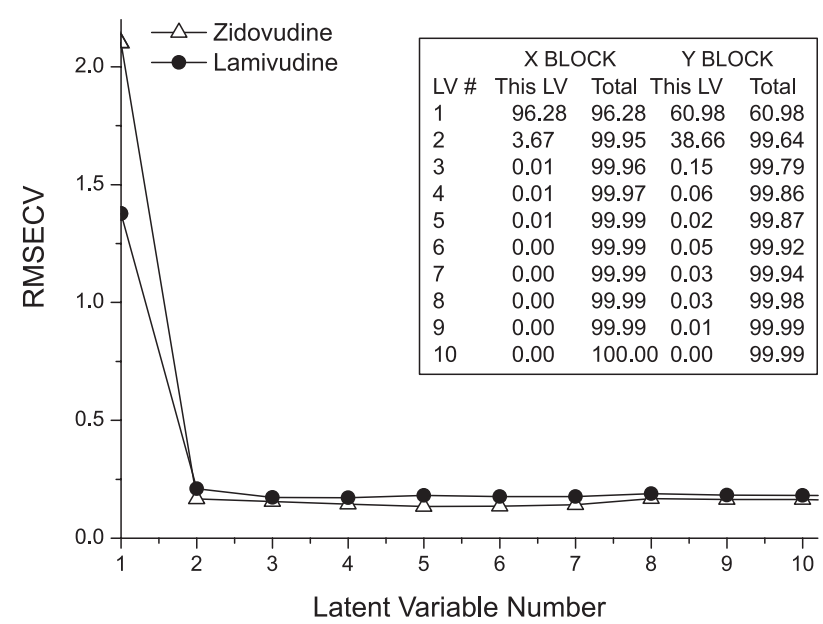

Figure 3. Evolution of the RMSECV value and the captured variance (inner table) as a function of the number of latent variables.

Studentized residues versus leverage graphs (results not shown). Considering limiting values of \pm 2.5 and $3(\mathrm{LV}) / \mathrm{n}$, respectively, anomalies were not observed in the calibration set. Finally, the prediction capacity of the multivariate model was appraised in regards to the external validation set (RMSEP: 0.3527 for AZT and 0.1168 for 3TC) and the cross-validation routine (RMSECV: 0.1553 for AZT and 0.1734 for 3TC). The results (Figure 5) indicated good prediction capacity with correlation coefficients (r) higher than 0.994 in all cases.

The best multivariate model, developed from meancentered spectral signals and using 3 latent variables, was applied to the analysis of commercial drugs containing the AZT/3TC association. The results (Table 3) from this model indicated a good agreement between multivariate and chromatographic methods, with maximum relative errors lower that $10 \%$.

\section{Validation of the multivariate methodology}

The spectroscopic multivariate methodology was validated according to guidelines from the $\mathrm{ICH}$, which included precision, accuracy, linearity and robustness assessments. Repeatability and intermediate precision evaluations showed relative standard deviations (RSD)

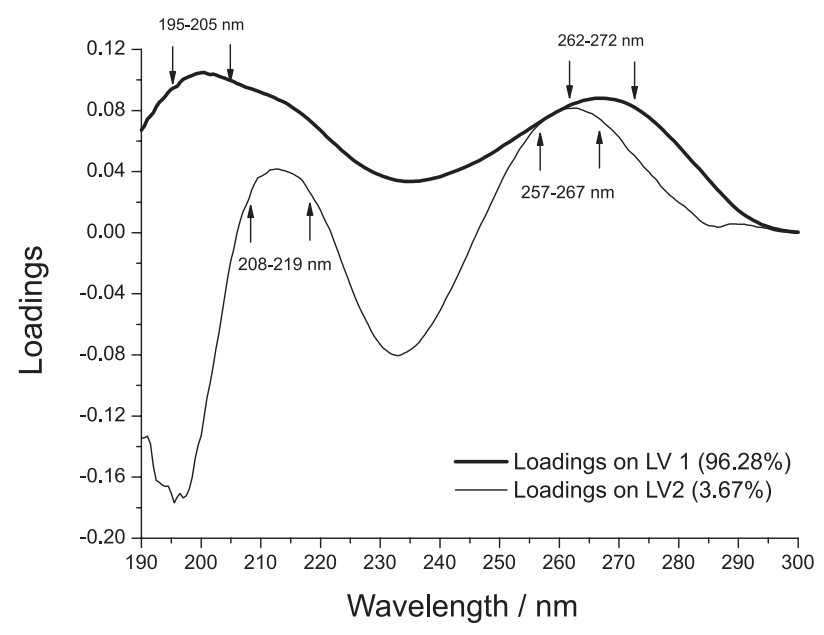

Figure 4. Loading for LV1 and LV2 in multivariate models developed with mean centered spectral data.
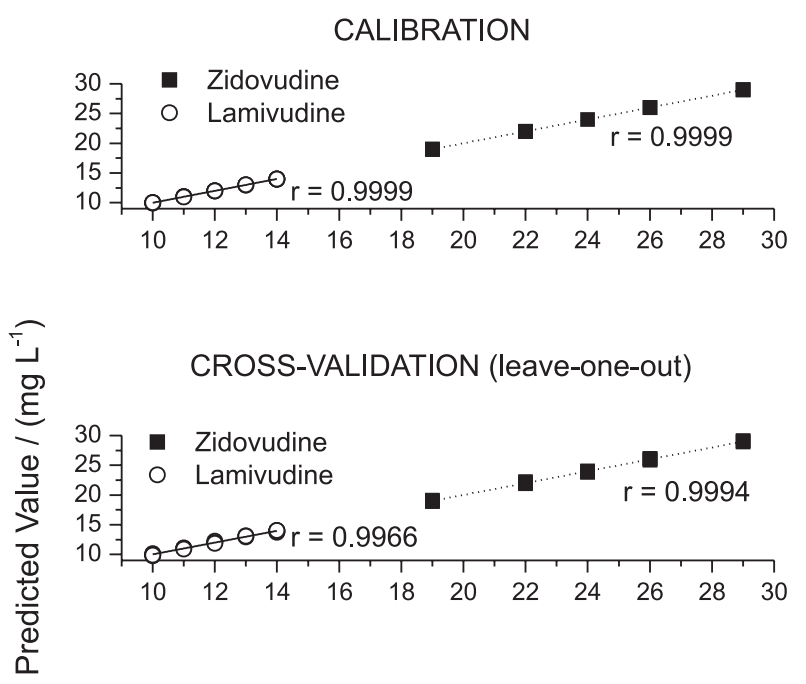

EXTERNAL VALIDATION

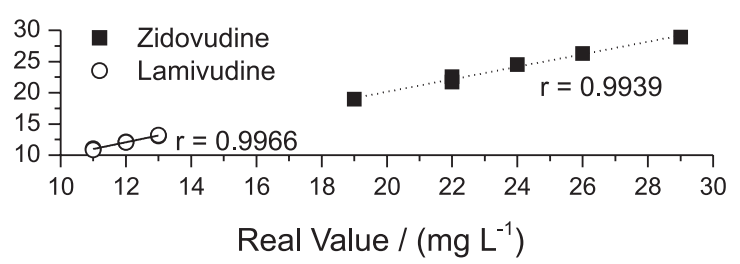

Figure 5. Correlation between real and predicted concentration of AZT and $3 \mathrm{TC}$ in validation (cross and external) and calibration sets.

Table 3. Results from the chromatographic and multivariate spectroscopic determinations of AZT and 3TC in commercial formulations

\begin{tabular}{|c|c|c|c|c|c|c|c|c|}
\hline \multirow{3}{*}{$\begin{array}{l}\text { Commercial } \\
\text { Drug }\end{array}$} & \multirow{2}{*}{\multicolumn{2}{|c|}{$\begin{array}{l}\text { Nominal concentration } \\
\qquad\left(\mathrm{mg} \mathrm{L}^{-1}\right)\end{array}$}} & \multicolumn{4}{|c|}{ Predicted concentration $\left(\mathrm{mg} \mathrm{L}^{-1}\right)$ (relative standard deviation) } & \multirow{2}{*}{\multicolumn{2}{|c|}{ Error $(\%)$}} \\
\hline & & & \multicolumn{2}{|c|}{ HPLC } & \multicolumn{2}{|c|}{ Multivariate model } & & \\
\hline & AZT & $3 \mathrm{TC}$ & AZT & $3 \mathrm{TC}$ & AZT & $3 \mathrm{TC}$ & AZT & $3 \mathrm{TC}$ \\
\hline Reference & 24.00 & 12.00 & $21.07(1.28)$ & $12.17(1.04)$ & $21.59(0.58)$ & $11.40(0.15)$ & 2.47 & -6.36 \\
\hline Generic & & & $23.04(1.66)$ & $11.75(0.78)$ & $21.08(0.31)$ & $10.57(0.33)$ & -8.51 & -10.04 \\
\hline
\end{tabular}

Prediction error calculated with respect to the HPLC result. 
Table 4. Results of the precision and accuracy evaluations

\begin{tabular}{|c|c|c|c|c|c|c|c|}
\hline \multicolumn{8}{|c|}{ Repeatability } \\
\hline \multicolumn{4}{|c|}{ Zidovudine } & \multicolumn{4}{|c|}{ Lamivudine } \\
\hline $\begin{array}{c}\text { Real } \\
\left(\mathrm{mg} \mathrm{L}^{-1}\right)\end{array}$ & $\begin{array}{c}\text { Predicted } \\
(\text { mean, } \mathrm{n}=3)\end{array}$ & $\begin{array}{c}\text { RSD } \\
(\%)\end{array}$ & $\begin{array}{c}\text { Recovery } \\
(\%)\end{array}$ & $\begin{array}{c}\text { Real } \\
\left(\mathrm{mg} \mathrm{L}^{-1}\right)\end{array}$ & $\begin{array}{c}\text { Predicted } \\
(\text { mean, } \mathrm{n}=3)\end{array}$ & $\begin{array}{c}\text { RSD } \\
(\%)\end{array}$ & $\begin{array}{c}\text { Recovery } \\
(\%)\end{array}$ \\
\hline 19.00 & 19.54 & 0.06 & 102.84 & 10.00 & 9.91 & 0.31 & 99.10 \\
\hline 24.00 & 23.87 & 0.07 & 99.46 & 12.00 & 11.70 & 0.24 & 97.50 \\
\hline 29.00 & 28.83 & 0.08 & 99.41 & 14.00 & 13.70 & 0.07 & 97.86 \\
\hline Mean & & 0.07 & 100.57 & Mean & & 0.21 & 98.15 \\
\hline \multicolumn{8}{|c|}{ Intermediate precision } \\
\hline \multicolumn{4}{|c|}{ Zidovudine } & \multicolumn{4}{|c|}{ Lamivudine } \\
\hline $\begin{array}{c}\text { Real } \\
\left(\mathrm{mg} \mathrm{L}^{-1}\right)\end{array}$ & $\begin{array}{c}\text { Predicted } \\
(\text { mean, } \mathrm{n}=6)\end{array}$ & $\begin{array}{c}\text { RSD } \\
(\%)\end{array}$ & $\begin{array}{c}\text { Recovery } \\
(\%)\end{array}$ & $\begin{array}{c}\text { Real } \\
\left(\mathrm{mg} \mathrm{L}^{-1}\right)\end{array}$ & $\begin{array}{c}\text { Predicted } \\
(\text { mean, } \mathrm{n}=6)\end{array}$ & $\begin{array}{c}\mathrm{RSD} \\
(\%)\end{array}$ & $\begin{array}{c}\text { Recovery } \\
(\%)\end{array}$ \\
\hline 19.00 & 19.79 & 0.28 & 104.18 & 10.00 & 9.93 & 0.20 & 99.30 \\
\hline 24.00 & 24.43 & 0.64 & 101.79 & 12.00 & 11.64 & 0.39 & 97.00 \\
\hline 29.00 & 29.11 & 0.33 & 100.38 & 14.00 & 13.69 & 0.10 & 97.79 \\
\hline Mean & & 0.42 & 102.12 & Mean & & 0.23 & 98.03 \\
\hline
\end{tabular}

RSD = relative standard deviation

Table 5. Evaluation of the robustness considering the effect of temperature, measurement time and $\mathrm{pH}$ on the prediction capacity of the multivariate methodology

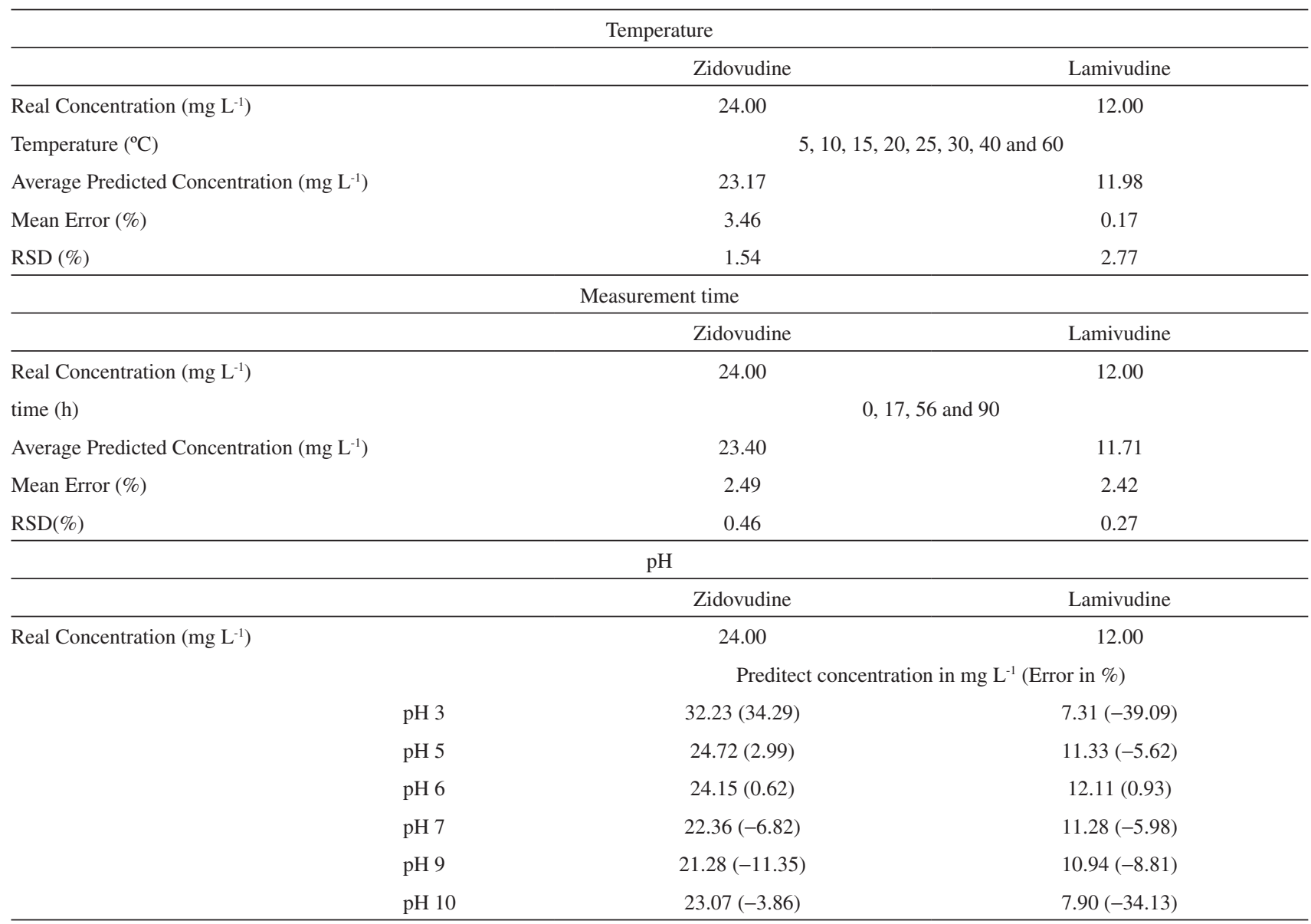

RSD $=$ relative standard deviation. 
lower than $0.5 \%$ (Table 4), values in accordance with Brazilian legislation ${ }^{21}$ which demands a maximum RSD of $5 \%$. The accuracy of the method was also confirmed through recovery tests (Table 4), with results from 97.79 to $104.18 \%$.

As it can be observed in Table 5, the results of the proposed methodology were not significantly modified by deliberate changes of the temperature and measurement time. In general, RSD values lower than $3 \%$ were observed between measurements carried out in different conditions. In contrast, changes to the $\mathrm{pH}$ of the samples led to higher RSD values, mainly due to modifications of the spectral profile of the drugs. AZT and 3TC have pKa values of 9.8 and 4.3, respectively, a fact that implies significant modification of the protonation equilibrium in $\mathrm{pH}$ values higher than 9.8 or lower than 4.3. As expected from these observations, the prediction capacity of the multivariate methodology was seriously reduced at alkaline $(\mathrm{pH} 10)$ or acidic $(\mathrm{pH} 3)$ conditions, with prediction errors higher that $30 \%$. The precision capacity was observed to improve when working between $\mathrm{pH} 5$ and 7, with prediction errors lower than $7 \%$. Very low prediction errors were observed at $\mathrm{pH}$ $6(<1 \%)$, which corresponds to the $\mathrm{pH}$ of the calibration samples.

\section{Conclusions}

The spectral interference observed between lamivudine and zidovudine hinders the analysis of associations of these two compounds by conventional external calibration systems. This spectral overlap can be overcome by using smoothed and first-derivative signals, a pre-processing system that generates prediction errors lower than $2.5 \%$ in the external validation process. In addition, multivariate models elaborated with mean-centered signals and using 3 latent variables have prediction errors lower than 1.3\% in the external validation process. In terms of the analysis of commercial drug associations, prediction errors lower than $10 \%$ were routinely observed, in relation to results from the standard chromatographic method. Validation studies have shown precision and accuracy results that are compatible with Brazilian legislation for the determination of lamivudine/zidovudine associations.

\section{Acknowledgments}

The authors are grateful to CAPES (Coordenação de Aperfeiçoamento de Pessoal de Nível Superior) for the scholarship granted and to CNPq (Conselho Nacional de Desenvolvimento Científico e Tecnológico) for the financial support.

\section{References}

1. Khoshayand, M. R.; Abdollahi, H.; Shariatpanahi, M.; Saadatfard, A.; Mohammadi, A.; Spectrochim. Acta, Part A 2008, 70, 491.

2. Kapoor, N.; Khandavilli, S.; Panchagnula, R.; J. Pharm. Biomed. Anal. 2006, 41, 761.

3. Goicoechea, H. C.; Olivieri A. C.; J. Pharm. Biomed. Anal. 1999, 20, 681.

4. De Córdova, M. L. F.; Barrales, P. O.; Torne, G. R.; Diaz, A. M.; J. Pharm. Biomed. Anal. 2003, 31, 669.

5. Amin, A. S.; Ragab, G. H.; Saleh, H.; J. Pharm. Biomed. Anal. 2002, 30, 1347.

6. Rojas, F. S.; Ojeda, C. B.; Anal. Chim. Acta 2009, 635, 22.

7. Escandar, G. M.; Damiani, P. C.; Goicoechea, H. C.; Olivieri, A. C.; Microchem. J. 2006, 82, 29.

8. Dinc, E.; Baleanu, D.; Ioele, G.; De Luca, M.; Ragno, G.; J. Pharm. Biomed. Anal. 2008, 48, 1471.

9. Ni, Y.; Qi, Z.; Kokot, S.; Chemom. Intell. Lab. Syst. 2006, 82, 241.

10. De Luca, M.; Oliverio, F.; Loele, G.; Ragno, G.; Chemom. Intell. Lab. Syst. 2009, 96, 14.

11. Kenney, K. B.; Wring, S. A.; Carr, R. M.; Wells, G. N.; Dunn, J. A.; J. Pharm. Biomed. Anal. 2000, 22, 967.

12. United States Pharmacopeia National Formulary, $30^{\text {th }}$ ed., US Pharmacopeial Convention, Rockville, MD, USA, 2007.

13. Pendela, M.; Van Gyseghem, E.; Van den Mooter, G.; Baert, L.; Hoogmartens, J.; Adams, E.; J. Pharm. Biomed. Anal. 2009, 49, 508.

14. Beck, R. C. R.; Cardoso, S. G.; Athayde, M. L.; Codevilla, C.; De Oliveira, F. K.; Dalmora, S. L.; Quim. Nova 2007, 30, 1225.

15. Lavra, Z. M. M.; Rolim Neto, P. J.; Silva, R. M. F.; Medeiros, F. P. M.; Quim. Nova 2008, 31, 969.

16. Sekar, R.; Azhaguvel, S.; J. Pharm. Biomed. Anal. 2005, 39,653.

17. Habte, G.; Hymete, A.; Mohamed, A. M. I.; Anal. Lett. 2009, 42,1552 .

18. Uslu, B.; Özkan, S. A.; Anal. Chim. Acta 2002, 466, 175.

19. Abdellatef, H. E.; Ayad, M. M.; Soliman, S. M.; Youssef, N. F.; Spectrochim. Acta, Part A 2007, 66, 1147.

20. ICH, International Conference on Harmonization, ICH Q2(R1), Guidance on Validation of Analytical Procedures: Text and Methodology, Geneva, 2005.

21. Agência Nacional de Vigilância Sanitária (ANVISA); Guia para Validação de Métodos Analíticos e Bioanalíticos, Resolução-RE No. 899, Brasil, 2003.

Submitted: April 20, 2010

Published online: October 7, 2010

FAPESP has sponsored the publication of this article. 